\section{Pathways to psychiatric care for children and adolescents at a tertiary facility in northern Nigeria}

\author{
Jibril O. Abdulmalik, ${ }^{1}$ Shehu Sale ${ }^{2}$ \\ 1Department of Psychiatry, University \\ of Ibadan; 2Department of Psychiatry, \\ Aminu Kano Teaching Hospital, Kano, \\ Nigeria
}

\section{Abstract}

There is limited availability of mental health services in Nigeria, and indeed most of Africa. Available services are also often under-utilized because of widespread ignorance and supernatural beliefs about the etiology of mental illnesses. The consequence, therefore, is a long and tedious pathway to care for the mentally ill, especially children and adolescents. This was a study of all new patients, aged 18 years and below, presenting over a 6 month period in 2009 (January - June) at the outpatient clinic of a tertiary psychiatric facility in northern Nigeria. A socio-demographic questionnaire was utilized, along with a record of the clinician's assessment of diagnosis for 242 patients. Subjects who had been withdrawn from school, or any previously engaged-in activity for longer than 4 weeks on account of the illness, were recorded as having disability from the illness. The children were aged 1-18 years (mean $=12.3 ; \mathrm{SD}=5.2$ ) with males accounting for $51.7 \%$ (125) while $14.5 \%$ of the females $(n=117)$ were married. Two thirds (64.5\%) of the patients had been ill for longer than 6 months prior to presentation. One hundred and forty four subjects (59.5\%) had received no care at all, while $36.4 \%$ had received treatment from traditional/religious healers prior to presentation. The most disabling conditions were ADHD (80\%), mental retardation (77.8\%), epilepsy (64.1\%) and psychotic disorders (50\%). There is urgent need for extending mental health services into the community in order to improve access to care and increase awareness about effective and affordable treatments.

\section{Introduction}

Nigeria is a West African Country with a significantly youthful population of 140 million people; $44 \%$ of whom are aged 14 years and below, while $5 \%$ are 60 years and older. ${ }^{1}$ The country is classified as a low-income group by the World Bank (2004 criteria). The proportion of health budget to GDP is $3.4 \%$ while the proportion of the capital budget allocated to health is about $5 \%$.

The majority of the diverse cultures in the country subscribes to supernatural beliefs about the causation of mental illness and frequently present to traditional or religious healers for the treatment of mental illnesses. ${ }^{2}$ Children and adolescents are particularly vulnerable as they do not partake in the decision making process, but can only seek care, at the discretion and through the pathways that the parents may choose. Cases of child abuse and neglect often result from accusations of witchcraft or demonic possession due to widespread ignorance about the nature and causes of mental illness. ${ }^{3}$ It has been documented that some mothers of children with intellectual disabilities in Lagos, had considered doing away with their children. ${ }^{4}$ Similarly, another report from south west Nigeria reported that seizure disorder and intellectual disabilities were common among abandoned children brought to a juvenile remand home in Ibadan, for care and protection. ${ }^{5}$ It can only be hypothesized that perhaps some of these mothers may have abandoned the children on the streets, consequent to the high burden of care, ignorance about available treatments and the associated stigma. The country has relatively poor mental health indices, with the total number of psychiatric beds per 10,000 population at 0.4 ; number of psychiatrists per 100,000 population at 0.09 ; number of psychiatric nurses per 100,000 population is 4 ; number of neurologists per 100,000 population is 0.02 ; number of psychologists per 100,000 population is 0.02 ; and the number of social workers per 100,000 population is $0.02 .{ }^{1}$ This situation is even more worrisome because where mental health services are available, they may be grossly underutilized due to the misconceptions about the causes and available treatment of mental disorders, including neurological conditions like epilepsy, which is also poorly understood and is usually construed as a form of mental illness. These ignorance and stigmatization often results in delay in seeking treatment or not getting any treatment at all. It is therefore important to understand the pathways to care for the mentally ill, especially among children and adolescents, and the sources of information available to caregivers, about mental health services. This information should provide useful guidance for public mental health efforts aimed at promoting awareness about mental disorders and encouraging early presentation for treatment.

\section{Materials and Methods}

This study was conducted from January to
Correspondence: Dr. Jibril 0. Abdulmalik, Department of Psychiatry, College of Medicine, University of Ibadan, Nigeria.

Tel. +234.8073839840 .

E-mail: jfutprints@yahoo.com

Key words: pathway, children, adolescents, northern Nigeria.

Acknowledgements: the assistance of Dr. S Gbamgbola and Dr. O. Beida was invaluable to the completion of this work, having assisted with data collection and data analysis respectively. Preliminary findings of this work were presented orally, at the $19^{\text {th }}$ World Congress of the International Association of Child and Adolescent Psychiatry and Allied Professions (IACAPAP), in Beijing, China, in June 2010.

Conflict of interest: the authors report no conflicts of interest.

Received for publication: 19 July 2011. Accepted for publication: 22 August 2011.

This work is licensed under a Creative Commons Attribution NonCommercial 3.0 License (CC BYNC 3.0).

(C)Copyright J.O. Abdulmalik and S. Sale, 2011 Licensee PAGEPress, Italy

Journal of Public Health in Africa 2012; 3:e4 doi:10.4081/jphia.2012.e4

June 2009 at the outpatient clinic of the Federal Neuropsychiatric Hospital (FNPH), Maiduguri, northern Nigeria. Maiduguri is the capital city of Borno state, in the north-eastern fringe of Nigeria, sharing borders with Cameroun, Chad and the republic of Niger. The FNPH Maiduguri is a tertiary psychiatric facility, which serves most of the north-eastern states, including patients from the neighboring countries of Chad, Niger and Cameroun.

All the new patients who were aged 18 years and below, presenting during the study period were approached, with their caregivers, and their informed consent and assent was obtained, after explaining the study to them. A socio-demographic questionnaire was utilized for the interview, prior to the clinical encounter with the psychiatrist. Disability was recorded to be present if the child had been withdrawn from school or previously engagedin activity for more than 4 weeks, on account of the illness. The questionnaire was subsequently included in the patients' folder, and the clinical assessment of diagnosis was documented by the physician, after the clinical encounter.

Ethical clearance was obtained from the Institution's Ethics and Research Board prior to the commencement of the study. The data obtained was subjected to descriptive and inferential analysis using the SPSS version 16 software. 


\section{Results}

Two hundred and forty two (242) respondents, aged $1-18$ years (mean=12.3; $\mathrm{SD}=5.2$ ) were interviewed, with males accounting for $51.7 \%$ (125) while $14.5 \%$ of the females $(n=117)$ were married. Two thirds of the respondents (67.3\%) were accompanied by either one or both parents, while the others came in company of other relatives. Greater than half (53.7\%) of the children were neither attending school nor engaged in any other activity but were staying at home (Table 1).

The majority of the subjects had not received any care prior to presentation (59.5\%) while about one third (36.4\%) had initially received treatment from a traditional/religious healer (Figure 1). Caregivers' level of education and socioeconomic status was not significantly correlated with health seeking pathway; but those accompanied by both parents to the psychiatric facility were 2.5 times more likely to have been ill for less than six (6) months (OR=2.5, 95\% CI, 2.35-2.6).

The most common presentations were epilepsy (42.6\%), neurologic conditions (19.4\%) and psychoses (10.7\%); while the most disabling were ADHD (80\%), mental retardation (77.8\%), epilepsy (64.1\%) and psychotic disorders (50\%). Two thirds (64.5\%) of the patients had been ill for longer than 6

Table 1. Sociodemographic characteristics of clinic attendees.

\begin{tabular}{|c|c|}
\hline $\begin{array}{l}\text { Sociodemographic } \\
\text { variable }\end{array}$ & $\begin{array}{c}\text { n (\%), total } \\
n=242\end{array}$ \\
\hline \multicolumn{2}{|l|}{ Gender } \\
\hline Male & $125(51.7)$ \\
\hline Female & $117(48.3)$ \\
\hline \multicolumn{2}{|l|}{ Marital status } \\
\hline Single & $216(89.3)$ \\
\hline Married* & $25(10.3)$ \\
\hline Divorced $^{\circ}$ & $1(0.4)$ \\
\hline \multicolumn{2}{|l|}{ Educational status } \\
\hline Primary & $37(15.3)$ \\
\hline Secondary & $47(19.4)$ \\
\hline Tertiary & $2(0.8)$ \\
\hline Islamiyya\# & $5(2.1)$ \\
\hline None & $151(62.4)$ \\
\hline \multicolumn{2}{|l|}{ Occupational status } \\
\hline Formal student & $86(35.5)$ \\
\hline Islamiyya student & $5(2.1)$ \\
\hline Menial worker & $7(2.9)$ \\
\hline Housewife & $14(5.8)$ \\
\hline At home (not working/studying) & $130(53.7)$ \\
\hline \multicolumn{2}{|l|}{ Accompanied by } \\
\hline One parent & $138(57)$ \\
\hline Both parents & $25(10.3)$ \\
\hline Grandparent(s) & $6(2.5)$ \\
\hline Other relatives & $54(22.3)$ \\
\hline Non relatives & $19(7.9)$ \\
\hline
\end{tabular}

*Twenty one (84\%) were females; ' female; \#informal Quranic schools. months prior to presentation (Figure 2)

The sources of information (Figure 3) for caregivers about available mental health services were predominantly from community members and neighbors (65\%), followed by the mass media (15\%).

\section{Discussion}

This study found a very high proportion of children and adolescents suffering from mental and neurological disorders not receiving any treatment at all for many years. Those who eventually receive treatment, four out of ten times would have presented to the traditional/ religious healers prior to presenting at the mental health facility.

It is sobering to note that nearly two thirds of the children and adolescents had been ill for longer than 6 months prior to presentation at the psychiatric facility, for conditions with readily available, effective and affordable treatments. This pattern of health-seeking behavior may be explained by the pervasive supernatural beliefs about the etiology of mental disorders and the associated stigma of the mentally

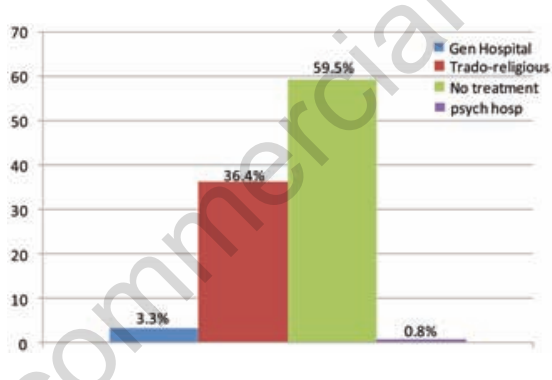

Figure 1. Pathway to care.

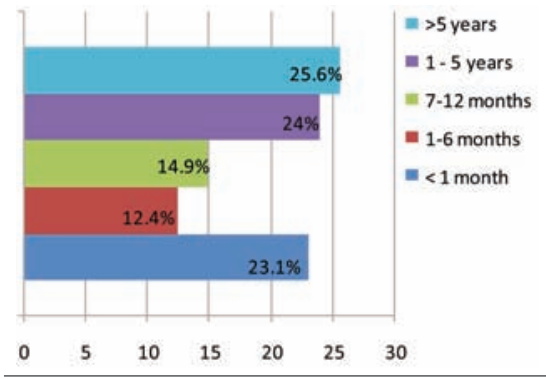

Figure 2. Duration of illness.

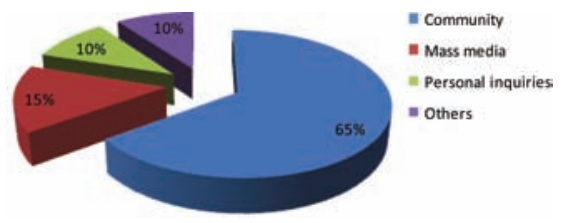

Figure 3. Sources of information. ill and their families. ${ }^{6}$ This explanation may also account for epilepsy and neurologic conditions being the most common presentations in this study; as epilepsy is often viewed in this environment, to be a form of mental disorder.

The majority (about eight in every ten) of those who were married were females. This may not be unconnected with the cultural practice of early girl marriages in the study setting. The Demographic and Health Survey (DHS) reported that north-eastern Nigeria had the second highest rate of teenage marriages, as $59 \%$ of female teenagers surveyed were already married. ${ }^{7}$

Attention deficit hyperactivity disorder (ADHD) and mental retardation were the most disabling conditions in this study, with epilepsy and psychotic disorders ranking third and fourth respectively. Mental retardation's degree of disability may be understandable on account of the chronic burden of care required, but ADHD is somewhat less easily explained, but may have resulted from persistent difficulties in managing their behavior on an ongoing basis.

The disability from epilepsy may largely be due to the pervasive stigmatization of the condition, rather than the actual burden of care, thus resulting in the inability to continue their previously engaged in activities. These areas would require more in-depth studies to clarify the situation better, with respect to the disability accruing from mental disorders in children and adolescents in this environment, and the factors contributing to the observed pattern.

A report among new outpatient respondents at a tertiary psychiatric facility in Ethiopia, reported that $30.9 \%$ had previously sought for healing via traditional and religious healers prior to presentation at the facility. ${ }^{8}$ A study from Bangladesh also indicated that $22 \%$ had previously sought for treatment from traditional healers. ${ }^{9}$

The finding in this study that $36.4 \%$ had sought for traditional and religious treatment prior to presentation is however, a lower estimate compared to a previous report from south west Nigeria, which indicated that more than half of the respondents (54\%) had previously sourced for care from traditional/religious healers. $^{2}$

A significantly more different picture is obtained from the developed countries where reports of pathway to care for the mentally ill is more likely to indicate referral rates from general practitioners, private practice and self referrals, ${ }^{10,11}$ indicating the disparity influenced by the different cultural and developmental norms and practices. The deep seated cultural misconceptions about the causation of mental illness in the study setting ${ }^{6}$ may account for the absence of any significant association between caregiver's level of education and the pathway adopted for seeking treat- 
ment for mental disorders.

It is noteworthy that the commonest source of information about mental health services was via community networks and neighbors, and this communication channel may be utilized effectively in public health promotion efforts and interventions, guided through the primary health care system in order to enhance acceptability.

This work is limited by its cross sectional design which is not powered to establish causal relationships for the determinants of pathway chosen to seek health care interventions for mental disorders in children and adolescents. Furthermore, information was not gathered on the beliefs systems of caregivers with respect to etiology of mental disorders, and to determine the impact (if any), that this had on the pathway chosen for seeking care. Significantly however, it has described the prevailing pathways to care, the clinical presentations and the resultant disability accruing from these conditions in the study setting.

\section{Conclusions}

The majority of young people with mental illness in northern Nigeria suffer significant morbidity and disability as they often receive little or no treatment, and this care is frequently provided by traditional/religious healers. Community-based enlightenment campaigns and public mental health efforts, through the successful integration of mental health into primary health care, may be an effective strategy to mitigate this problem.

\section{References}

1. WHO. Country profile of Nigeria. Mental Health Atlas of the WHO, pp. 348-351. Geneva, WHO Press, 2005.

2. Abiodun OA. Pathways to mental health care in Nigeria. Psychiatr Serv 1995;46:823-6.

3. Omigbodun 00. Mental health services for children in Nigeria: where should the focus be? Arch Ibadan Med 2003;4:9-12.

4. Abasiubong F, Obembe A, Ekpo E. The opinion and attitued of mothers to mental retardation in Lagos, Nigeria. Nigerian $\mathrm{J}$ Psychiat 2008;6:80-5.

5. Bella TT, Adejumo 0, Omigbodun 00. Partnership with a faith based organization to provide mental health care to children: opportunities and conflicts. Paper presented at the 18th World Congress of the Int. Assoc. for Child and Adolescent
Psychiatry and Allied Professions (IACAPAP), Istanbul, Turkey, 2008.

6. Gureje 0, Lasebikan VO, EphraimOluwanuga 0 , et al. Community study of knowledge of and attitude to mental illness in Nigeria. Brit J Psychiat 2005;186:43641.

7. National Demographic and Health Survey. In: Makinwa-Adebusoye P. Hidden: a profile of married adolescents in Northern Nigeria. 2003 [Accessed 20 April 2011] Available from http://www.actionhealthinc.org/

8. Bekele YY, Flisher AJ, Alem A, Baheretebeb Y. Pathways to psychiatric care in Ethiopia. Psychol Med. 2009;39:475-83.

9. Giasuddin NA, Chowdhury NF, Hashimoto $\mathrm{N}$, et al. Pathways to psychiatric care in Bangladesh. Soc Psychiatry Psychiatr Epidemiol 2010 [Epub ahead of print].

10. Amaddeo F, Zambello F, Tansella M, Thornicroft G. Accessibility and pathways to psychiatric care in a community-based mental health system. Soc Psychiatry Psychiatr Epidemiol 2001;36:500-7.

11. Fujisawa D, Hashimoto N, MasamuneKoizumi Y, et al. Pathway to psychiatric care in Japan: a multicenter observational study. Int J Ment Health Syst 2008;2:14. 